\title{
Characterization of the thermophysiological comfort of duvets in consideration of the bed cave
}

\author{
Dr. Bianca-Michaela Wölfling ${ }^{1 *}$, Dr. Edith Classen ${ }^{1}$, Dr. Anja Gerhardts ${ }^{1}$ \\ ${ }^{1}$ Hohenstein Institut für Textilinnovation $\mathrm{GmbH}$, Bönnigheim, Germany \\ ${ }^{*}$ Corresponding author E-mail address: b.woelfling@hohenstein.de
}

\section{INFO}

CDAPT, ISSN: 2701-939X

peer reviewed article

2020, Vol.1, Nr. 1, pp. 39-47

DOI:10.25367/cdatp.2020.1.p39-47

Received: 06 May 2020

Accepted: 10 August 2020

Available online: 22 September 2020

\section{Keywords}

duvets,

bed cave,

sweating, thermal manikin,

thermophysiological comfort,

\begin{abstract}
Sleep is a fundamental need for humans. On average $1 / 3$ of the lifetime is spent in bed. Important for a healthy sleep is the duvet. This should have sufficient heat insulation and should ensure a dry bed climate at the same time. The thermophysiological comfort of classic duvets can be rated via skin model and thermal manikin. The simultaneous detection of dry and moist heat flux of duvets is now not possible.

The lecture presents results of the German funded project AiF 19522 N "Bed Cave and Comfort". Within the project the interaction of thermophysiological comfort during sleeping and the bed cave was investigated. Duvets with different filling materials (down and feathers, polyester, animal hair as well as new developments) were examined according the classical, thermophysiological evaluation method for sleep comfort. Furthermore, a new evaluation method for duvets with the sweating, thermal manikin Sherlock (Newton type, Thermetrics) was developed. During the measurement, a realistic sleep situation can be reconstructed with the sweating, thermal manikin. All measured data were validated by monitored sleep test within a climatic chamber.
\end{abstract}

(C) 2020 The authors. Published by CDAPT.

This is an open access article under the CC BY-NC-ND license https://creativecommons.org/licenses/ peer-review under responsibility of the scientific committee of the CDAPT. 


\section{Introduction}

Sleep is a fundamental an underestimated basic need of humans. On average $1 / 3$ of the lifetime is spent in bed. After 48 hours without sleep the concentration for simplest tasks is lost [1]. Restful sleep is very important for human regeneration and health maintenance [2].

During sleep a comfortable warm bed climate, night movements and a lowering of body temperature of $0.5^{\circ} \mathrm{C}$ with subsequent rise should be possible. Therefore, produced body heat is dissipated by the skin by radiation, conduction, and convection. Further sweating can occur to cool down the human body. To avoid moisture in the bed system sweat should be transported through the system during sleep [1]. Studies show that about one fifth of the produced heat and moisture produced during sleep is released to the mattress. The majority of $80 \%$ is released to the duvet [3]. Other components like mattress, linen or nightwear play a tangential role. So, the duvet should be able to transport the produced sweat to the ambient. Further the human body should not cool down during sleeping. Duvets must therefore have adequate thermal insulation.

Nowadays there are traditional filling of duvets like down and feathers, animal hair (e. g. sheep, camel) and nonwovens. In addition, new filling and insulation materials are used for duvets, e. g. nonwovens made from hemp fibers, microfine fiber structures, 3D knitted fabrics, polyester fiber balls, mixtures of different materials as well as new assemblies like zoned duvets with higher filling levels on the feed zone or open ventilation zones.

In the 1990s a method and model to characterize the comfort of duvets was invented at Hohenstein, which is still used today [4]. This evaluation system is based on two methods: dry heat insulation of ready-made duvets measured with the thermal manikin and the material-specific characteristics of heat and moisture transport determined with the Hohenstein skin model. The measurement of dry and wet heat flow of readymade duvets in consideration of the bed cave is until now not possible.

Further, the insulation of the duvet depends on the draping of the duvet and the so formed bed cave between human and duvet. This draping ability of the blanket depends on the material, the rigidity, the filling quantity, and the packaging. However, so far there are no scientific studies dealing with the ideal bed cavity for thermal insulation. With the 3D scanner technology, a powerful tool is available, with which a quantitative, exact 3D measurement of the bed cavity and draping of the duvet is possible.

Within a German funded research project AiF $19522 \mathrm{~N}$ a new measuring and evaluation method for traditional and new ready-made duvets in consideration of the bed cave was investigated. In addition, the bed cavity geometry is measured using 3D scanner technology and the influence of the bed cave and the enclosed air layer on the thermal insulation and sleeping comfort was researched.

\section{Materials and Methods}

Within the project more than 40 duvets with different cover materials and fillings e. g. polyester (PES), down and feathers, wool (WO), camel hair, cotton (CO) were investigated. Screening tests showed that 18 duvets represent state of the art of German duvets. These duvets were used for further investigation. Table 1 shows these duvets with the available product information. 
Table 1. Duvet materials.

\begin{tabular}{|c|c|c|c|c|c|c|}
\hline Sample & Cover material & Filling & Stitching & $\begin{array}{l}\text { Size } \\
{\left[\mathrm{m}^{2}\right]}\end{array}$ & $\begin{array}{l}\text { Weight } \\
\text { [kg] }\end{array}$ & $\begin{array}{l}\text { Thickness } \\
\text { [mm] }\end{array}$ \\
\hline M3 & $100 \% \mathrm{CO}$ & $100 \%$ PES & lengthwise & 2,91 & 1,282 & 28 \\
\hline M4 & $100 \%$ CO & $100 \%$ PES & lengthwise & 2,68 & 1,662 & 51 \\
\hline M5 & $100 \%$ CO & $\begin{array}{l}90 \% \text { down, } \\
10 \% \text { feather }\end{array}$ & square & 2,75 & 1,176 & $22 / 13$ \\
\hline M6 & $100 \% \mathrm{CO}$ & $100 \%$ down & lengthwise & 2,77 & 1,774 & $25 / 14$ \\
\hline M7 & - & $100 \%$ down & square & 2,90 & 1,746 & $19 / 14$ \\
\hline M8 & 100\% Lyocell & $\begin{array}{l}60 \% \text { Lyocell, } \\
40 \% \text { PES }\end{array}$ & square & 2,77 & 1,894 & $41 / 24$ \\
\hline M11 & $\begin{array}{l}50 \% \text { CO, } \\
50 \% \text { Lyocell }\end{array}$ & $\begin{array}{l}100 \% \text { PES- } \\
\text { hollow fiber }\end{array}$ & dots & 2,73 & 1,775 & $53 / 40$ \\
\hline M12 & $100 \%$ PES & $\begin{array}{l}100 \% \text { PES- } \\
\text { hollow fiber }\end{array}$ & flower shaped & 2,75 & 0,804 & 15 \\
\hline M13 & $100 \%$ CO & $100 \%$ Polylactide & body fit & 2,80 & 1,855 & $42 / 26$ \\
\hline M14 & $100 \%$ CO & $100 \%$ PES & body fit & 2,82 & 1,315 & $29 / 20$ \\
\hline M17 & $100 \%$ CO & $\begin{array}{l}100 \% \text { PES- } \\
\text { nonwoven }\end{array}$ & lengthwise & 2,63 & 1,197 & $21 / 14$ \\
\hline M18 & $100 \%$ CO & $100 \%$ PES & lengthwise & 2,7 & 1,286 & $19 / 14$ \\
\hline M20 & - & $100 \%$ WO & lengthwise & 2,68 & 1,843 & $27 / 25$ \\
\hline M21 & $100 \%$ CO & $100 \%$ WO & square & 2,68 & 1,288 & $15 / 9$ \\
\hline M25 & $\begin{array}{l}80 \% \text { micromodal, } \\
20 \% \mathrm{CO}\end{array}$ & $100 \%$ camel hair & body fit & 2,74 & 1,982 & 42 \\
\hline M28 & $100 \%$ CO & $\begin{array}{l}60 \% \text { linen, } \\
40 \% \mathrm{CO}\end{array}$ & $\begin{array}{l}\text { lengthwise with } \\
\text { circles }\end{array}$ & 2,90 & 1,142 & $9 / 8$ \\
\hline M29 & $\begin{array}{l}70 \% \text { micromodal, } \\
30 \% \text { CO }\end{array}$ & $100 \%$ PES & $\begin{array}{l}\text { Beads stitching } \\
\text { with ventilation } \\
\text { system }\end{array}$ & 2,76 & 1,715 & $41 / 36$ \\
\hline M32 & $\begin{array}{l}100 \% \text { CO, } \\
\text { climate zone: } 100 \% \\
\text { PES }\end{array}$ & $100 \%$ down & $\begin{array}{l}\text { cross with air } \\
\text { chambers }\end{array}$ & 2,91 & 1,121 & - \\
\hline
\end{tabular}

\subsection{Sweating, thermal manikin}

The Hohenstein evaluation system for duvets is based on two methods: dry heat insulation of ready-made duvets measured with the thermal manikin and the material-specific characteristics of heat and moisture transport determined with the Hohenstein skin model. The measurement of dry and wet heat flow of readymade duvets in consideration of the bed cave is until now not possible. Therefore, a new method was invented to characterize the thermophysiological comfort of duvets in consideration of surface coverage, snugness and the microclimate within the bed cave using the sweating, thermal manikin Sherlock (type Newton, Thermetrics).

The sweating, thermal manikin Sherlock has the anatomical shape of a human standard man (height 1.75 $\mathrm{m}$, body surface $1.85 \mathrm{~m}^{2}$, clothing size 50 ). The skin surface of the manikin was regulated to a constant temperature $T_{s}$ of $31^{\circ} \mathrm{C}$. The required electrical heating power $\mathrm{H}_{\mathrm{c}}$ for the constant surface temperature was the measured value, for the determination of the thermal resistance $R_{c}$ of duvets. The measurement was set in a climate chamber at temperature of $\mathrm{T}_{a}=15^{\circ} \mathrm{C}$ and relative humidity of $\mathrm{RH}_{a}=50 \% \mathrm{rh}$.

To create a realistic sleeping condition, the measurement took place with the sweating, thermal manikin Sherlock lying down, wearing a two-piece pajamas (CO). The head rest on a pillow. The duvet itself was measured without a cover. To record the microclimate of the bed cave, ten additional temperature and humidity sensors were attached to the sweating, thermal Manikin Sherlock, and the duvet (figure 1, middle). The duvet was draped uniformly around the manikin, which was covered up to the neck. Care was taken to ensure that the duvet lies loosely so that there is enough air volume in the bed cave". A standard bed construction consisting of a tubular steel bed frame with a one-piece foam mattress (180 
$\mathrm{mm}$ thick), which is covered with a cotton sheet, was chosen for the investigation. Figure 1 shows the measurement setup for evaluating duvets with the sweating, thermal Manikin Sherlock.

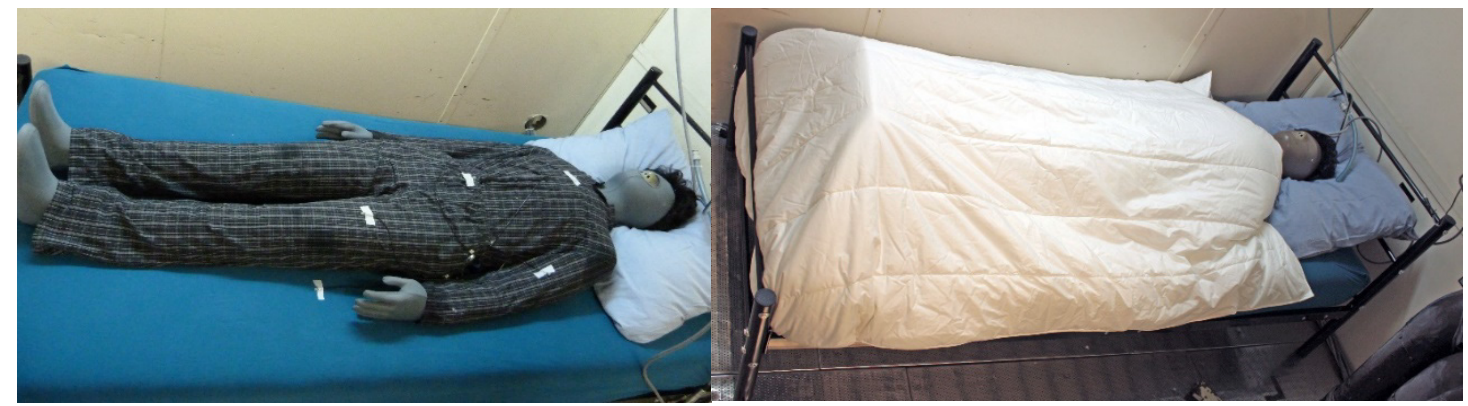

Fig. 1 Measurement setup to characterize the thermophysiological parameters of duvets with the sweating, thermal manikin Sherlock (type Newton, Thermetrics); left: dressed Sherlock equipped with temperature and humidity sensors lying on mattress and bed frame, right: complete measurement setup.

In addition to these investigations of the thermal resistance $R_{c}$, realistic sweating during sleep was simulated with Sherlock to determine the water vapor resistance $R_{e}$ of duvets. The same measurement setup was used for this. Sweating is achieved with the help of a tight sweat suit and sweat nozzles, which are distributed over the body. The sweat suit has the function of distributing the sweat (water) from the sweat nozzles evenly over the body. The sweat nozzles can be controlled individually, so different sweating rates can be set. Table 2 shows the used sweating rate, which are based on Park et al. [5]. The sweating nozzles on the back side were switched off because the measurements focus on the duvet and the microclimate within the bed cave. These sweating rates reproduce a realistic sleeping situation and leads to reproducible measurement results for duvets.

Table 2. Sweating rates during measurement of duvets with the sweating, thermal manikin Sherlock (type Newton, Thermetrics).

\begin{tabular}{llll}
\hline Manikin zone & $\begin{array}{l}\text { Sweating rate } \\
{\left[\mathbf{m l} / \mathbf{h r ~}^{\mathbf{2}}\right]}\end{array}$ & Manikin zone & $\begin{array}{l}\text { Sweating rate } \\
{\left[\mathbf{m l} / \mathbf{h r ~}^{\mathbf{2}}\right]}\end{array}$ \\
\hline face & 0 & lower back & 0 \\
head & 0 & right upper thigh front & 15 \\
right upper arm front & 58 & right upper thigh guard & 0 \\
right upper arm back & 0 & right upper thigh back & 0 \\
left upper arm front & 58 & left upper thigh front & 15 \\
left upper arm back & 0 & left upper thigh guard & 0 \\
right forearm front & 18 & left upper thigh back & 0 \\
right forearm back & 10 & right lower thigh front & 18 \\
left forearm front & 18 & right lower thigh back & 0 \\
left forearm back & 10 & left lower thigh front & 18 \\
right hand & 72 & left lower thigh back & 0 \\
left hand & 72 & right calf front & 17 \\
upper chest & 16 & right calf back & 0 \\
shoulders & 0 & left calf front & 17 \\
stomach & 17 & left calf back & 0 \\
mid back & 0 & right foot & 65 \\
waist & 15 & left foot & 65 \\
\hline
\end{tabular}

\subsection{Subject trial}

To validate the results with the thermal, sweating manikin subject trials with selected duvets M5, M14 and M32 were done. Five male subjects (table 2) performed monitored sleep experiments in the climate chamber. The subjects were healthy men. Before the study, the participating subjects were given detailed information about the schedule of the test series after a medical check, were informed about possible risks, gave their consent to the tests, and confirmed their voluntary participation. 
Table 3. Sample of subjects.

\begin{tabular}{llllll}
\hline Subject & $\begin{array}{l}\text { Age } \\
\text { [years] }\end{array}$ & $\begin{array}{l}\text { Height } \\
{[\mathbf{c m}]}\end{array}$ & $\begin{array}{l}\text { Weight } \\
{[\mathbf{k g}]}\end{array}$ & $\begin{array}{l}\text { BMI } \\
{[\mathbf{]}}\end{array}$ & $\begin{array}{l}\text { Body Surface } \\
\text { DuBois } \\
{\left[\mathbf{c m}^{2}\right]}\end{array}$ \\
\hline TP1 & 28 & 184 & 79 & 23 & 2,02 \\
TP2 & 33 & 186 & 82 & 24 & 2,06 \\
TP3 & 30 & 172 & 65 & 22 & 1,77 \\
TP4 & 24 & 170 & 73 & 25 & 1,84 \\
TP5 & 29 & 182 & 81 & 24 & 2,02 \\
MW & 28,8 & 178,8 & 76 & 23,6 & 1,94 \\
Stdev & 3,2 & 7,3 & 7,1 & 1,1 & 0,1 \\
\hline
\end{tabular}

The monitored sleeping experiments were performed at $20{ }^{\circ} \mathrm{C}, 50 \% \mathrm{RH}$ in a climatic chamber with air movement $0.3 \mathrm{~m} / \mathrm{s}$. To create comparable conditions to the experiments with the sweating, thermal manikin Sherlock the subjects slept in the climatic chamber for at least 6 hours, wearing a pair of cotton underpants and a two-piece pajama out of cotton. The head rested on a pillow. The duvet itself was tested without a cover, using five temperature and humidity sensors to record the microclimate of the bed cave. The test bed was draped loosely by the test subjects, so that they formed a "sleeping cave". A "standard bed construction" was chosen for the present study. It consists of a tubular steel bed frame with a onepiece foam mattress ( $180 \mathrm{~mm}$ thick), which is covered with a cotton sheet. Figure 2 shows the experimental test setup during the monitored sleeping experiment with subjects.

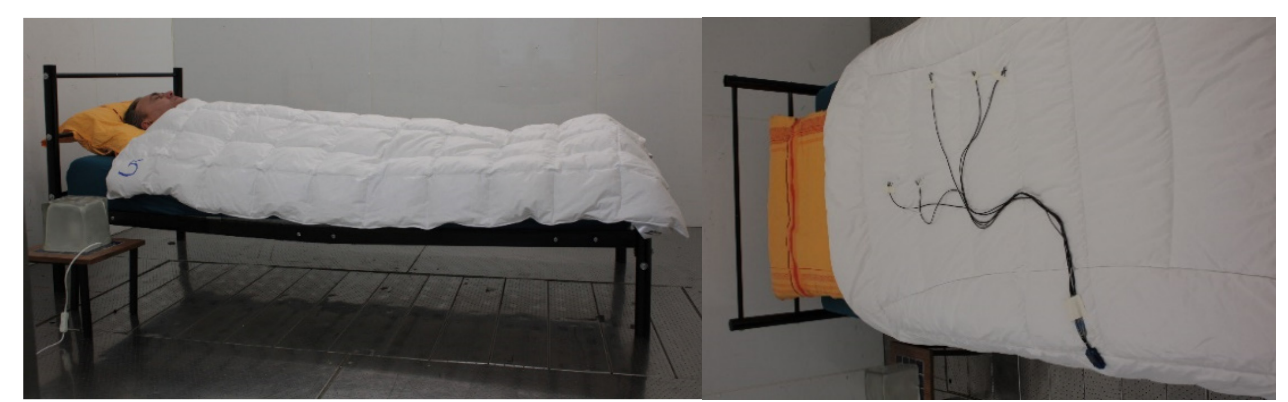

Fig. 2 Measurement setup "Sleeping trial" in climatic chamber with subject (left), position of temperature and humidity sensors (right, duvet turned for visualization).

The objective body data were recorded using various sensors. The heart rate was recorded using a chest strap (Polar WearLink). Temperature sensors $(T)$ for the skin temperature as well as combined temperature-humidity sensors ( $T, \mathrm{RH}$; MSR Electronics $\mathrm{GmbH}$ ) for recording the microclimate were distributed on the body surface in accordance with ISO 9886. To create a distance to the skin and thus to record the moisture in the microclimate between textile and skin, the sensor was attached to a spacer (thickness $3 \mathrm{~mm}$ ). In addition to the objectively recorded measured values, the subject's subjective sensations after the sleep were queried and recorded using a questionnaire.

Before sleeping experiments, the test subjects were equipped with the sensors and get dressed. This process took at least 30 minutes to also acclimatize the subjects. The individual experiments each lasted at least 6 hours, during which the test subjects slept in a bed under the respective duvet.

Furthermore, the change in weight of the test subjects and the sweat absorption of the individual items of clothing and the duvet were determined by weighing before and after the sleep experiment. For this purpose, the test subjects and the clothing were weighed before and after the experiment. 


\section{Results and Discussion}

\subsection{Sweating, thermal manikin}

The investigations with the sweating, thermal manikin Sherlock indicate that it is possible to determine the thermal resistance $R_{c}$ and water vapor permeability $R_{e}$ of duvets. Table 4 shows the results of these characterizations. Regarding the thermal resistance $R_{c}$ the values are in the rage $0.56-1.00 \mathrm{~m}^{2} \mathrm{~K} / \mathrm{W}$. M28 shows the lowest thermal resistance with $0.56 \mathrm{~m}^{2} \mathrm{~K} / \mathrm{W}$ (table 4). Therefore, this duvet is less insulating and should be used as summer duvet. Duvets M5, M8, M17, M18, M20 and M32 have $R_{c}$-values in the middle range between $0.61-0.72 \mathrm{~m}^{2} \mathrm{~K} / \mathrm{W}$. The residual duvets M3, M4, M6, M7, M11, M12, M13, M14, M21, M25, M29 show high thermal resistance values in the range $0.75-1.00 \mathrm{~m}^{2} \mathrm{~K} / \mathrm{W}$ (table 4 ). So, the thermal insulation of these duvets can be rated as high and they should be used in winter when the ambient temperature in bedrooms is low.

Table 4. Thermal resistance $R_{c}$ and water vapor resistance $R_{e}$ of different duvets measured with sweating, thermal manikin Sherlock.

\begin{tabular}{lll}
\hline Sample & $\begin{array}{l}\text { Thermal resistance } \mathbf{R}_{\mathbf{c}} \\
{\left[\mathbf{m}^{\mathbf{2}} \mathbf{K} / \mathbf{W}\right]}\end{array}$ & $\begin{array}{l}\text { Water vapor resistance } \mathbf{R}_{\mathbf{e}} \\
{\left[\mathbf{m}^{\mathbf{2}} \mathbf{P a} / \mathbf{W}\right]}\end{array}$ \\
\hline M3 & 0.77 & 98.78 \\
M4 & 0.76 & 82.93 \\
M5 & 0.61 & 64.86 \\
M6 & 0.96 & 104.84 \\
M7 & 1.00 & 102.54 \\
M8 & 0.72 & 73.98 \\
M11 & 0.87 & 100.09 \\
M12 & - & 54.09 \\
M13 & 0.77 & 83.13 \\
M14 & 0.75 & 73.33 \\
M17 & 0.65 & 66.85 \\
M18 & 0.69 & 68.23 \\
M20 & 0.71 & 84.74 \\
M21 & - & 61.54 \\
M25 & 0.95 & 92.48 \\
M28 & 0.56 & 51.89 \\
M29 & 0.87 & 84.69 \\
M32 & 0.62 & 60.15 \\
\hline
\end{tabular}

The results of water vapor resistance $R_{e}$ are in the range $51.89-104.84 \mathrm{~m}^{2} \mathrm{~Pa} / \mathrm{W}$. Especially duvet $\mathrm{M} 28$ and $\mathrm{M} 12$ has low $\mathrm{R}_{\mathrm{e}}$-values, which means these duvets have a good breathability and during sleep produced sweat can be transported through the duvet to the ambient. The highest water vapor permeabilities have the duvets M6 and M7 with values in the range $102.54-104.84 \mathrm{~m}^{2} \mathrm{~Pa} / \mathrm{W}$. This can be explained, among other things, by the high thickness of the duvet. The by human produced sweat (water vapor) must pass through more material before it can be released into the ambient. The results show no correlation between the $\mathrm{R}_{\mathrm{e}}$-value and the filling or stitching design of the duvets.

In addition, the microclimate in the bed cave was determined during the measurements of the water vapor resistance by ten temperature and humidity sensors. Figure 4 shows the average temperature (orange, left) and relative humidity (blue, right) in the bed cave during the measurements of the water vapor resistance $R_{e}$ using the sweating, thermal manikin Sherlock. There are slight differences in the microclimate of the bed cave for different duvets. The temperature is between $25.67-28.89^{\circ} \mathrm{C}$. The lowest temperatures in the bed cave were achieved for duvet M3 and M28, for duvets M11, 21 the highest. In the case of relative humidity in the bed cave, the values are in the range of $54.43-67.43 \% \mathrm{RH}$. From a clothing physiological point of view, the relative humidity should be below $60 \% \mathrm{RH}$, because at higher relative humidity's no differentiation can be made by humans and it is sensed as unpleasant wet. The duvets M14 
and M28 have the lowest relative humidity in the bed cave during the determination of the water vapor resistance. The duvets $\mathrm{M} 7$ and M11 the highest relative air humidity in the bed cave.
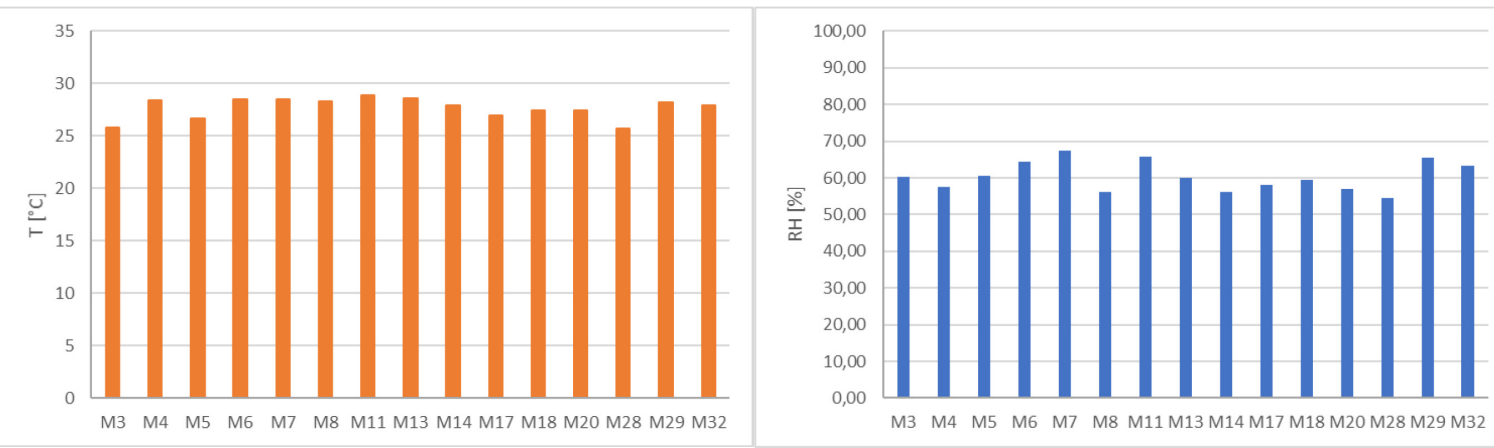

Fig. 4 Temperature $T$ (left) and relative humidity $R H$ (right) in the bed cave during the measurements of the water vapor resistance $R_{e}$ using sweating, thermal manikin Sherlock

There are no apparent correlations between water vapor resistance $R_{e}$ measured with the sweating, thermal Manikin Sherlock and the climate in the bed cave.

\subsection{Subject Trial}

During the monitored sleeping experiments the test subjects produced a small amount of sweat between $275 \mathrm{~g}$ and $490 \mathrm{~g}$ (table 5). Most of the produced sweat P evaporates, i.e. 95.54\% (M32) - 97.27\% (M14) (ratio evaporated sweat E/produced sweat $P$ ) were transported through the duvet and released into the environment. In the duvets themselves, $1.31 \mathrm{~g}$ (M5), $1.62 \mathrm{~g}$ (M14) and $3.91 \mathrm{~g}$ (M32) remain over the entire monitored sleeping experiment (table 5). This means that only very small amounts of sweat remain in the duvets. The results show clearly that while sleeping under the duvet M32, which has climatic zones, the subjects produces less sweat. Simultaneous duvet M32 absorbs the highest amount of sweat.

The results of the individual monitored sleeping experiments were evaluated. The data was analyzed subject-specific and product-specific. The mean values across all subjects were calculated. Due to the large number of data, the following results are limited to mean values of the recorded objective data (skin temperature, temperature in the microclimate, humidity in the microclimate) for all duvets on lower back right position.

Table 5. Produced and evaporated sweat amount during subject trial.

\begin{tabular}{llcc}
\hline Clothing & \multicolumn{2}{c}{ Amount of sweat [g] } \\
& M5 & M14 & M32 \\
\hline Subject & 490.00 & 461.11 & 275.00 \\
Underpants & 1.17 & 0.89 & 1.18 \\
Pajama shirt & 1.80 & 4.76 & 2.44 \\
Pajama trousers & 7.59 & 2.59 & 1.24 \\
Duvet & 1.31 & 1.62 & 3.91 \\
Cushion & 0.98 & 2.07 & 2.23 \\
Bed sheet & 0.70 & 0.68 & 1.26 \\
\hline Produced Sweat P [g] & 490.00 & 461.11 & 275.00 \\
Evaporated sweat E [g] & 476.46 & 448.50 & 262.74 \\
E/P [\%] & 97.24 & 97.27 & 95.54 \\
\hline
\end{tabular}

Figure 5 shows the relative humidity (right) in the microclimate above the skin of the subject on lower back right position. All three duvets M5 (grey curve), M14 (orange curve) and M32 (blue curve) show the same curve progression with minor differences for the individual duvets. Towards the end of the sleep period of six hours, however, trends can be seen. M32 tends to have the lowest moisture in the microclimate above the skin, M14 the highest. This confirms the measurements with the sweating, thermal Manikin Sherlock. 
Here M14 has the highest water vapor resistance $R_{e}$ compared to the duvets M5 and M32. Low water vapor resistance $R_{e}$ means produced sweat is transported through the duvet to the ambient. In case of higher values this transport is less efficient and the relative humidity in the microclimate above the skin rises.

By comparing the temperature in the microclimate (figure 5, right) above the skin of the subject on lower back right position of the three duvets similar curve progression can be seen, too. This is not surprising considering that these duvets have slightly differences in the thermal resistance $R_{c}$ (table 4). The measurement fluctuations within curve M14 on the lower back right can be explained by averaging over all subjects. M14 has the highest thermal resistance, which means thermal insulation, of these three samples. It is therefore not surprising that the temperature in the microclimate of the bed cave is higher in the case of M14 than in the other duvets. Duvet M14 has the higher $R_{e}$-value compared to M5 and M32, but the relative humidity in the microclimate is almost the same for these three duvets during the subject trail. Furthermore, the subject produced $461.11 \mathrm{~g}$ of sweat in case of M14, which is greater than M32 and a little bit lower than M5. That implies that M14 puffers more sweat than M5 and M32.
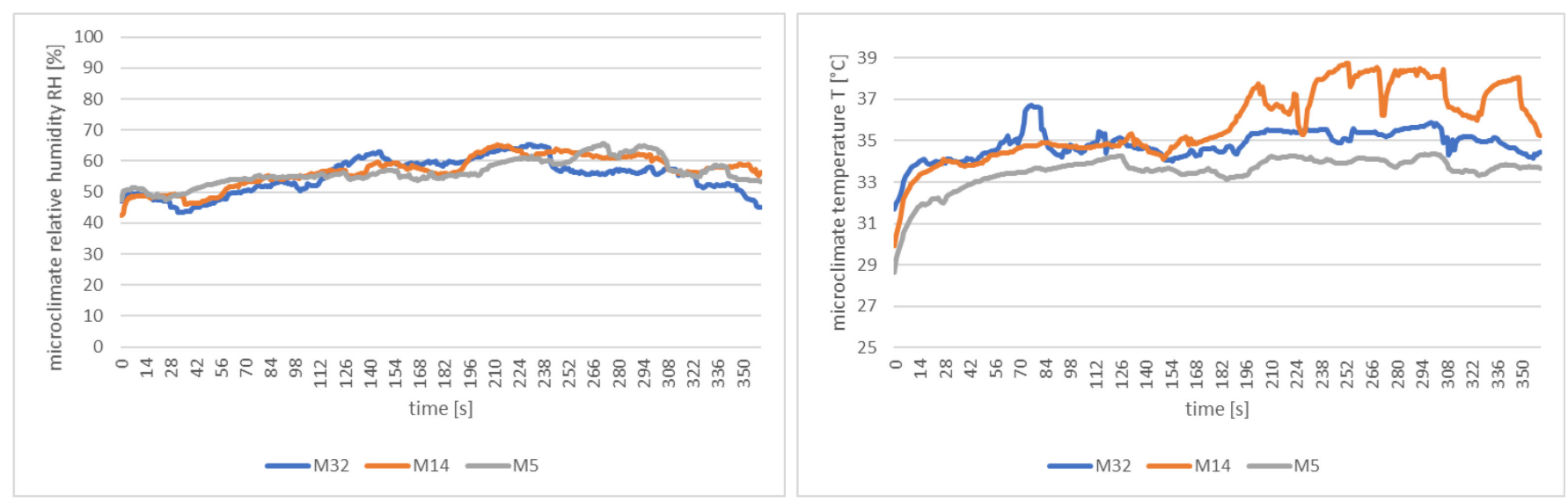

Fig. 5 Relative humidity RH (left) and Temperature T (right) in the microclimate above the skin on lower back right position during monitored sleeping experiment with subjects.

Figure 6 shows the skin temperature on lower back right position during the monitored sleeping experiment. The values show, as before the temperature in the microclimate, that the three duvets slightly differ in their thermal resistance. It can be said that the lowest skin temperatures occur while sleeping under the duvet M32. Compared to M5 and M14, this duvet also has the lowest thermal resistance (Table 4).

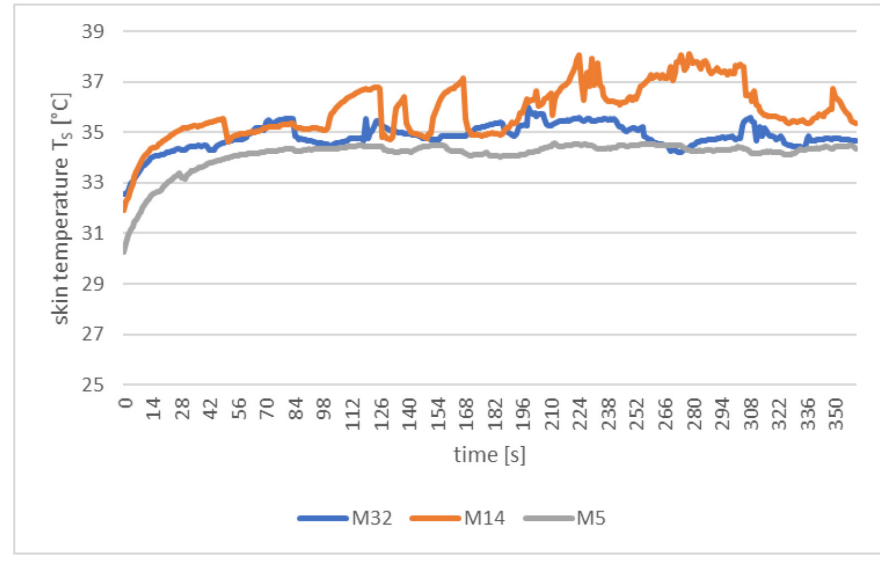

Fig. 6 Skin temperature $T_{s}$ on lower back right position during monitored sleeping experiment with subjects.

After each individual sleeping experiments, the subjects filled out a detailed standardized questionnaire for the duvets M5, M14 and M32. This questionnaire includes questions about the feeling and comfort of the duvets, as well as the overall comfort. These detailed questions are relevant for the overall 
assessment, to be able to classify the thermophysiological properties of duvets and the measurements with the sweating, thermal manikin Sherlock.

The examined duvets differ in terms of their stitching: M5 square, M14 body fit and M32 cross- with air chambers (table 1). The subjects did not notice any of these stitching negatively. They were consistently rated with grade 2 (good).

The evaluation of the temperature shows only slight differences between the samples. Duvets M5 and M32 are classified as comfortable (grade 2, good), M14 as comfortable-warm (grade 2.7, satisfactory) and thus as a little bit warmer and uncomfortable. This reflects the measurement data of the skin temperature on the lower back right (figure 6).

The moisture sensation of the three duvets differ slightly, too. While duvet M5 is described as dry, M14 and M32 is classified as slightly damp. The perception of moisture by the subjects is still described as good (grade 2). In addition, no humidity accumulation is felt in all duvets.

Overall, the thermophysiological comfort of duvet M5 is rated with a grade of 1.7, followed by M32 with 2.2 and M14 with 2.6. This shows clearly that there are only slight differences between the individual perception of these three duvets.

\section{Conclusions}

Within the German funded IGF research project AiF 19522 N "Bed Cave and Comfort", a new system for characterizing the thermophysiological comfort of duvets should be developed, which can objectively assess the heat and moisture management of duvets considering the shape and size of the bed cave. For this purpose, a suitable measuring method was developed to characterize the thermal resistance $R_{c}$ (thermal insulation) and the water vapor resistance $R_{e}$ (breathability) with the sweating, thermal manikin Sherlock. It became apparent that in manikin measurements by considering the bed cave a higher information content for characterizing the clothing-physiological comfort of duvets is obtained. Based on sleep tests with subjects, these thermophysiological indicators as well as the measurement method for the sweating, thermal manikin Sherlock could be validated. The new measurement method with the sweating, thermal manikin Sherlock is suitable for characterization of the thermophysiological comfort of duvets. Here, classic as well as innovative duvets can be assessed regardless of the filling used, and the construction and manufacture of the duvets. Conventional clothing physiological characterizations with the Hohenstein skin model do not have to be carried out and there is no loss of information in accuracy and significance.

\section{Acknowledgements}

IGF project $19522 \mathrm{~N}$ was founded through the AiF within the framework of the program for promotion of cooperative industrial research (IGF) by the German Federal Ministry for Economic Affairs and Energy based on a resolution by the German Bundestag.

\section{References}

[1] J. Zulley, Barmer GEK Deutsche Akademie für Gesundheit und Schlaf (DAGS), 5. Auflage, Juli 2011

[2] J.A. Hobson, Sleep. Scientific American Library, A Division of HPHLP" New York, ISSN 1040-3213, 1989

[3] Caps R \& Umbach KH., Ermittlung der Komfortkriterien bei Körperruhe. Schlussbericht AiF-Nr. 6419, Bönnigheim, 1988

[4] Umbach KH. Bewertungssystem für den physiologischen Schlafkomfort von Bettdecken. Hohensteiner Report (59):41, 2003

[5] Park, S.J. and T. Tamura, Distribution of evaporation rate on human body surface. The Annals of Physiological Anthropology Journal, 1992. Nov, 11(6): p. 593-609 